\title{
GM-K562 Cell Vaccine
}

National Cancer Institute

\section{Source}

National Cancer Institute. GM-K562 Cell Vaccine. NCI Thesaurus. Code C52190.

A cell-based vaccine comprised of K562 cells transfected with the granulocyte macrophage-colony stimulating factor (GM-CSF) gene with potential immunopotentiating properties. Vaccination with GM-K562 cells may stimulate the host immune system to produce an antitumoral T-lymphocyte response, thereby inhibiting tumor growth. K562 cells are derived from the human erythroleukemia cell line K562. GM-CSF (also known as sagramostim) expressed by vaccine cells binds to specific cell surface receptors, modulating the proliferation and differentiation of a variety of hematopoietic progenitor cells with some specificity towards stimulation of leukocyte production. GM-CSF also promotes antigen presentation, up-regulates antibodydependent cellular cytotoxicity (ADCC), and increases interleukin-2-mediated lymphokineactivated killer cell function; it may also augment host antitumoral immunity. 